\title{
Reducing Uncertainties in Hydrocarbon Volumetric Estimation: A Case Study of Fuba Field, Onshore Niger Delta
}

\author{
Fubara Franklin, Nnamdi J. Ajah, Jude U. Igweajah, Yinka A. Olayinka, \\ Abdulmaliq Abdulsalam and Paul Mogaba
}

\begin{abstract}
Reducing uncertainties to the barest minimum before reserve estimation aids in making a better decision regarding field development. This study analyses uncertainty in hydrocarbon reserve estimation in Fuba Field using both scenario-based deterministic and stochastic methods. Two hydrocarbon reservoirs (A and I) were selected and mapped. Depth structure maps revealed fault supported collapsed crestal closures for both reservoirs. Uncertainty analysis was conducted using low case (P90), base case (P50), and the high case (P50) reservoir properties. On average, porosity, NTG and Sw are $31 \%, 89 \%, 10 \%$, and $24 \%, 84 \%, 23 \%$ for $A$ and $I$ reservoirs. Hydrocarbon volumes recorded for the high case, base case, and low case using a deterministic versus stochastic approach are 30.52 MMSTB, 12.46 MMSTB, 4.57 MMSTB, and 18.52 MMSTB, 13.59 MMSTB, and 9.40 MMSTB for reservoir A, 58.87 MMSTB, 10.94 MMSTB, 1.51 MMSTB, and 25.56 MMSTB, 14.59 MMSTB and 7.63 MMSTB for reservoir I. While the base case was similar for both methods (stochastic and deterministic), there is a huge difference in the low and high-case hydrocarbon volumes recorded in both methods. This change could be attributed to the reservoir bulk volume with $(>85 \%)$ with little contribution from oil saturation and porosity. Cross plot analysis confirms that bulk volume is the main control of the estimated stock tank original oil in place (STOIIP). Hence, a slight alteration in bulk volume will significantly affect the estimated STOIIP. It is recommended that bulk volume be given most attention when conducting reservoir simulation as this will increase simulation time, reduce simulation cost, and provide more accurate simulation results.
\end{abstract}

Index Terms - Bulk Volume, Deterministic, Stochastic, Uncertainty.

\section{INTRODUCTION}

Uncertainty is the recognition that results may always deviate from reality. There is widespread concern about

Submitted on November 29, 2020

Published on February 19, 2021.

Fubara Franklin, Center for Petroleum Geosciences, University of Port Harcourt, Nigeria.

(e-mail: ffubara01@gmail.com)

Nnamdi J. Ajah, Center for Petroleum Geosciences, University of Port Harcourt, Nigeria.

(e-mail: iamjosephajahnnamdi@gmail.com)

Jude U. Igweajah Center for Petroleum Geosciences, University of Port Harcourt, Nigeria.

(e-mail: judeigweajah@gmail.com)

Yinka A. Olayinka, Energy and Environmental Research Group, Department of Geology, University of Ibadan, Nigeria.

(e-mail: yinkaolayinka6@ gmail.com)

Abdulmaliq Abdulsalam, Department of Chemical and Petroleum Engineering, University of Lagos, Nigeria.

(e-mail: abdulmaliqbox ${ }^{@}$ gmail.com)

Paul Mogaba, DeGeoid Integrated Geoservices Limited, Nigeria

(e-mail: mogabapaul@gmail.com) quantities such as hydrocarbon in place, hydrocarbon reserves, and the time for the recovery process, which are all very critical inputs to the economic returns. These quantities play crucial roles in making important decisions for both the oil producers and investors at different reservoir development phases. Risks are present practically in all spheres of oil and gas production: from exploration for oil and gas to commercial development of resources (the seismic acquisition data, the processing of the data, interpretation, and even drilling). However, the simple analysis of risks is not sufficient. Hence, uncertainty studies are relevant to quantifying all the expected outcomes from producing any given hydrocarbon resource. There is a lack of data on various geological and geophysical features too frequently, resulting in measurement and model error [1].

In building a geological model, one must go through a thorough subsurface evaluation, including interpreting seismic data, performing the time-to-depth conversion, interpreting log data, establishing geological conceptual models, building a 3D reservoir model, and estimating fluid contacts and fluid types in the different areas. It is essential to acknowledge that these steps incur some level of uncertainties, both in the data used, the selection of data to be used, and the data's interpretation. It is essential to include all these uncertainties in the value chain into volume estimation [2]. These uncertainties are summarized into; Structural, Fluid contact, Petrophysical, and PVT (Bo and $\mathrm{Bg}$ ) Uncertainties [3].

The sources of structural depth uncertainty include (1) velocity model; (2) time interpretation pick; (3) isochore thickness; and (4) fault interpretation. These translate to well-seismic miss-tie, horizon miss-pick, fault misrepresentation, and conversely reflect on the structural depth map.

The petrophysical uncertainties are associated with the estimation of NTG, porosity, water saturation, and permeability. For porosity, for example, the porosities considered are vertical averages over reservoir thickness. There are two essential sources of porosity uncertainty.

The first is related to logging tool measurement, processing, and interpretation. The second is associated with the sampling of wells. Additionally, the impact of internal porosity trends is independent of the relationship of the directions to the structure and contacts, so they need to be quantified separately. As with porosity related uncertainty, there are also uncertainties associated with water saturation and permeability. Since petrophysical parameters are estimated using empirical equations, there is a considerable amount of uncertainty in their input parameters [4]. 
The uncertainties in the expansion factors; $\mathrm{Bo}$ and $\mathrm{Bg}$ are relatively small and mainly due to uncertainty in the lab results. The fluids change significantly across the field, incurring considerable uncertainty in segments with no fluid samples. This uncertainty is estimated using information from the drilled wells and the variation in fluid properties across the field.

Uncertainty analysis methods provide comprehensive ways to evaluate and compare the degree of risk and uncertainty associated with each stage of hydrocarbon developments. The methods utilized for quantifying uncertainties can broadly be divided into two groups; deterministic and stochastic methods. In the deterministic approach, the actual observed measurements are used to quantify the uncertainty. Meanwhile, the stochastic (probabilistic) approach utilizes several random measurements (often called realizations) constrained by a lower limit and an upper limit. This study evaluates uncertainties in hydrocarbon volume estimation in the Fuba Field, located in the Swamp depobelt of the Niger Delta Sedimentary basin, Nigeria (see Fig. 1).

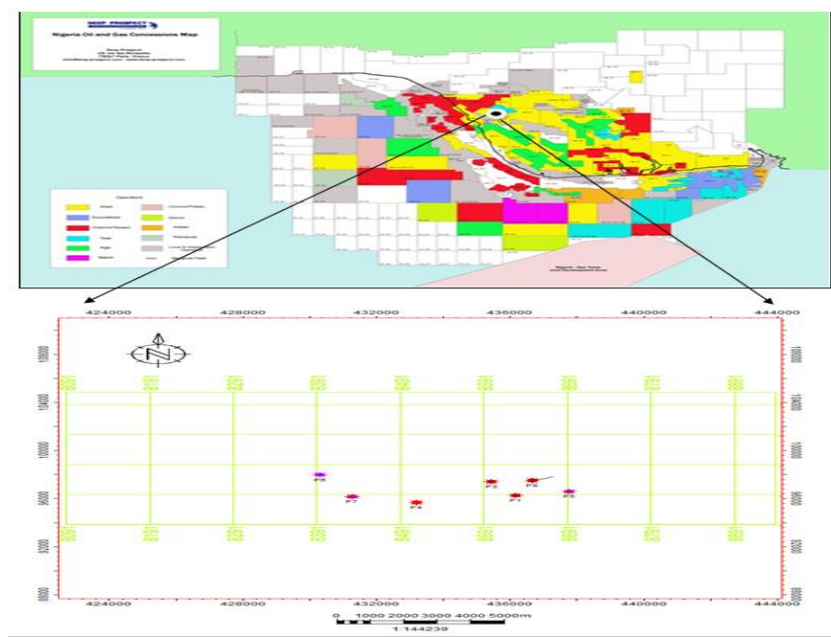

Fig. 1. Map of Niger Delta Oilfields showing the location of 'Fuba' Field

\section{GEOLOGY}

The Delta is located at Guinea's Gulf's apex towards Africa's west coast and Nigeria's South-South geopolitical zone. The Delta sits in a failed arm of a rifted triple junction created during the South Atlantic Ocean opening in LateJurassic to Cretaceous times[5].

Stratigraphically, the Delta is subdivided into three stratigraphic units, and from oldest to youngest includes; Akata Formation, Agbada Formation, and Benin Formation [6]. These three Tertiary formations all sit on the older Cretaceous Benue trough. The Paleocene Akata formation is the oldest unit in the Tertiary Niger Delta (Fig. 2). The Formation comprises marine shales, with few sandstone lenses, silt, and turbiditic sands. The sand shale ratio in this Formation is $20 \%$ to $80 \%$. The Formation is believed to be the primary source rock in the Delta [7]. The Eocene Agbada formation rests conformably on the Akata Formation; this Formation is the primary reservoir rock unit in the basin and is composed of paralic sedimentation; interbeddings of sands and shales [8]. The sands are thinner at the base, and their thickness increases towards the top where they are composed almost entirely of sands. Generally, Agbada formation is composed of a $60 \%$ to $40 \%$ sand shale ratio. The Oligocene Benin Formation is the youngest in the Delta (Fig. 2), composed of predominantly Continental River with an average thickness of $3050 \mathrm{~m}$ [9]. The Formation's Top is composed mainly of alluvium and is believed to be deposited in the alluvial or upper coastal plain environments.

The structures prevalent in the basin are growth faults, rollover anticlines, synthetic and antithetic faults, and collapsed crestal structures. [5] Revealed that hydrocarbons are found in both the upthrown and downthrown faulted blocks in the Delta.

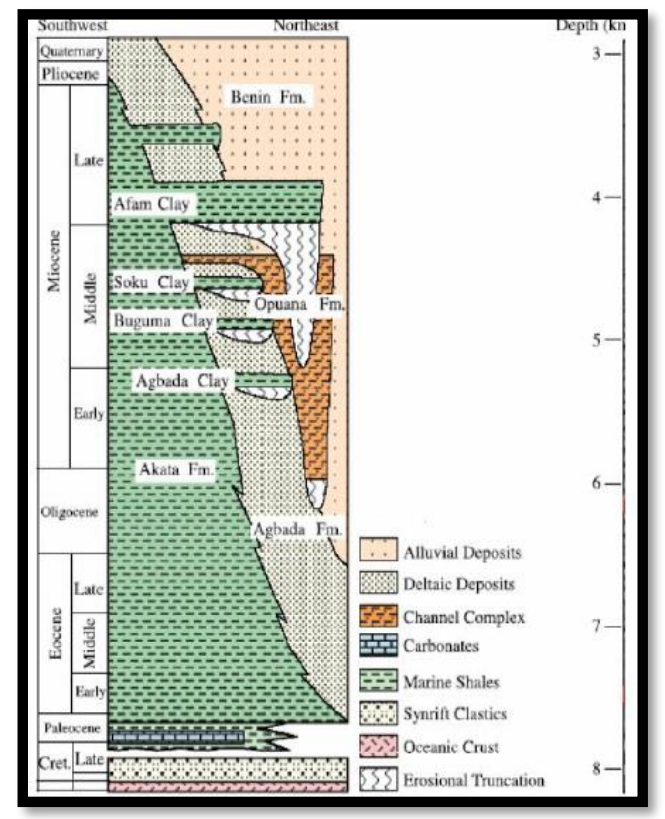

Fig. 2. A cross-section of Niger Delta stratigraphy [5]

\section{MATERIALS AND METHODS}

Data utilized for this study includes 3-D post-stack depthmigrated seismic data, well headers, well deviations, well logs (F1-F5), and check shot for F1. A flowchart of the employed is shown in Fig. 3 below. After data loading and conditioning, the routine static modelling procedure was followed. Lithology discrimination was achieved using gamma-ray and was validated using resistivity. In addition to picking reservoir top and base, the combination of gamma-ray, resistivity, sonic, and neutron-density log was used to identify reservoir fluid types and contacts. Since there was no biostratigraphy information, the reservoirs were carefully correlated across the five wells using log motif and marker shales situated above and below the reservoirs.

\section{A. Well-seismic Tie}

After de-spiking was achieved, the F1 check shot was used to calibrate the sonic log and subsequently for the generation of acoustic impedance log. Furthermore, the reflection coefficient $(\mathrm{Rc})$ and a synthetic seismogram were created. The Rc was convolved with a statistical wavelet extracted from the seismic, in the vicinity of well F1 to produce the synthetic seismogram. This seismogram was 
adjusted (bulk shift of $-3 \mathrm{~ms}$ ) to fit the original seismic while the time-depth relation function was used to generate the velocity model. As the well has been properly tied to the seismic data, the visualization of reservoirs on seismic to establish their continuity was possible.

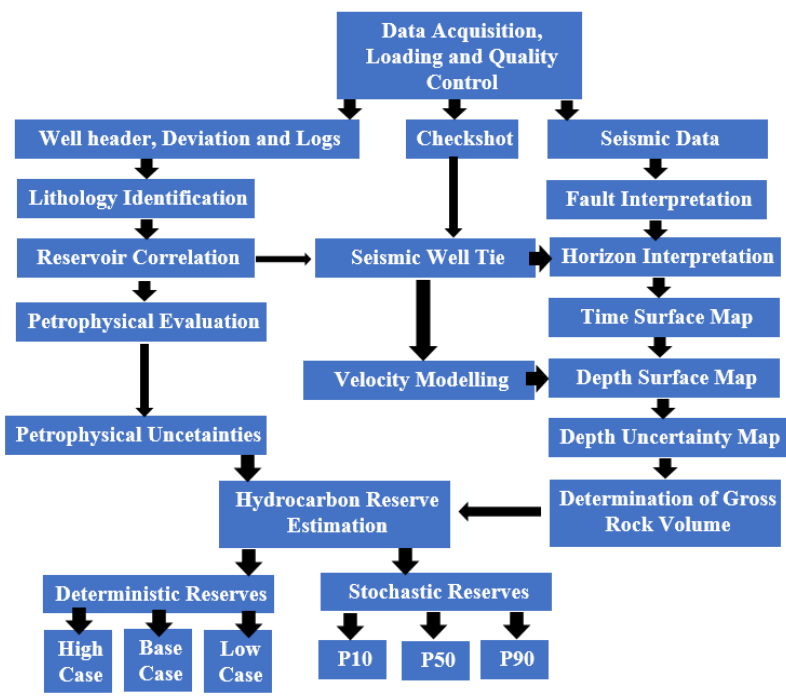

Fig. 3. Workflow utilized for the research work.

\section{B. Depth Uncertainty Evaluation}

Fault mapping was done on both the inline and crossline using variance attribute and was subsequently validated on the seismic slice (mapping interval of ten slices). Reservoir well logs information acted as a guide for mapping the horizons in both the crossline and inline. The mapping process began with large inline/crossline spacing intervals of 50 slices. Afterwards, the inline/crossline spacing was reduced to twenty-five slices, ten slices, and five slices. At the end of the horizon tracking process, a seed grid was generated. The seed grid was used in the time surface map generation, while the velocity model was used to convert the time surface map to a depth surface map. The depth map was flexed to the well tops, and a convergent algorithm was used to generate the residual surface (depth error) map. The uncertainty associated with the reservoir's depth was analyzed using the depth uncertainty map and the base case depth structural map (corresponds to P50 volume). The high case depth map (corresponds to P10 volume) is defined as; Base Case + Depth Uncertainty, while the low case depth map (corresponds to P90 volume) is defined as; Base Case Depth Uncertainty. The gross volume (GRV), which is the volume above the oil-water contact to the top of the reservoir was then estimated for the low case, the base case, and the high case scenarios.

\section{Reservoir Properties Uncertainty Evaluation}

The reservoir properties evaluated include hydrocarbon fluid contact (HC), shale volume (VSH), net to gross $(\mathrm{NTG})$, porosity $(\Phi)$, and water saturation $(\mathrm{SW})$. The resistivity $\log$ was used to establish hydrocarbon, while the Neutron and density differentiated the fluid types and their respective contacts. The VSH was a significant input for net sand calculation. Furthermore, it was estimated from the gamma-ray $\log$ using equations 1 and 2 [10]. Porosity was calculated using equations 3 and 4 [11]. Water saturation, which is the fraction of water occupied in reservoir rocks' pore space, was calculated using the Archie equation [12], [13].

$\mathrm{I}_{\mathrm{GR}}=\frac{G R_{\text {Log_- }_{-} G R_{\text {Min }}}}{G R_{\text {Max }}-G R_{\text {Min }}}$

$\left.\left.\mathrm{V}_{\mathrm{SH}}=1.7\left\lfloor(3.38)-\left(\mathrm{I}_{\mathrm{GR}}+0.7\right)^{2}\right)\right\rfloor\right)^{1 / 2}$

PHIT $=\frac{\rho_{\text {Matrix }-\rho_{\text {Bulk }}}}{\rho_{\text {Matrix }-\rho \text { Fliud }}}$

$P H I E=P H I T *\left(1-V_{S H}\right)$

$\mathrm{S}_{\mathrm{w}}{ }^{\mathrm{n}}=a \frac{R_{w}}{\phi^{m}}$

Where;

$\mathrm{I}_{\mathrm{GR}}=$ gamma ray index;

$\mathrm{GR}_{\mathrm{Log}}=$ gamma ray reading of formation;

$\mathrm{GR}_{\text {Min }}=$ minimum gamma ray (clean sand);

$\mathrm{GR}_{\text {Max }}=$ maximum gamma ray (shale);

$\rho_{\text {matrix }}=$ Matrix Density;

$\rho_{\text {bulk }}=$ Bulk Density;

$\mathrm{P}_{\text {fluid }}=$ Fluid Density;

PHIT=total porosity;

$\mathrm{S}_{\mathrm{w}}=$ water saturation;

$\mathrm{R}_{\mathrm{w}}=$ formation water resistivity;

$\varnothing=$ porosity;

$\mathrm{Rt}=$ formation resistivity;

$\mathrm{n}=$ saturation exponent;

$\mathrm{a}=$ cementation exponent.

\section{Hydrocarbon Reserve Calculation}

Hydrocarbon reserves were estimated by deterministic and stochastic based approach. Equation 6 shows the basic equation used for the hydrocarbon volume estimation.

STOIIP $=\frac{7758 \times \mathrm{A} \times \mathrm{h} \times \varnothing \times \mathrm{NTG} \times(1-\mathrm{Sw})}{\mathrm{FVF}}$

Where;

$A=$ Oilfield closure area $\left(\mathrm{m}^{2}\right)$

$h=$ Gross thickness $(m)$

$\emptyset=$ Effective porosity (in frac.)

$N T G=$ Net to Gross (in frac.)

$S W=$ Water saturation $($ in frac. $)$

$F V F=$ Formation Volume Factor

The P10 volumes were calculated using the maximum reservoir property values for porosity, water saturation, net to gross, and gross rock volume (area $\mathrm{x}$ thickness) for the deterministic reserve volumes. The P50 was calculated using the average values, while P90 was calculated using the minimum reservoir property values. For the stochastic reserve, almost all the parameters are assumed to have triangular distribution, except for the formation volume factor. (Since it gave distributions that fit best). To generate the reserves distribution, crystal ball software was used with over 10000 iterations generated. 


\section{RESULTS AND DISCUSSION \\ A. Reservoir Identification and Correlation}

The results for lithology and reservoir identification are presented in Fig. 4. A total of nine sand bodies (A, B, C, D, E, F, G, H, I) were identified and correlated across all seven wells in the field. Two reservoir sands were selected for this study (A and I).

\section{B. Petrophysical Evaluation}

The results of the petrophysical assessment are presented in Tables 1 and 2. Shale volumes range from 8 to $14 \%$ with an average of $11 \%$ in reservoir $\mathrm{A}$ and from 10 to $25 \%$ with an average of $16 \%$ in reservoir I. The net to gross ratio ranges from $86 \%$ to $92 \%$ with a mean of $89 \%$ in reservoir A, while in reservoir I, it ranged from $75 \%$ to $94 \%$ with an average of $84 \%$. On average, effective porosity in reservoir $\mathrm{A}$ and $\mathrm{I}$ are $28 \%$ and $24 \%$ respectively, suggesting the reservoirs are of outstanding quality. Water saturation ranges from $10 \%$ to $41 \%$ in reservoir $\mathrm{A}$ and 11 to $54 \%$ in reservoir I. On average, water saturation is $33 \%$ and $23 \%$ in reservoir A and reservoir I.

The results utilized for uncertainty evaluation in petrophysical properties for reservoir A and reservoir I are presented in Fig. 5. The low case properties were obtained from the lowest petrophysical properties in the reservoir. The high case was obtained from the highest petrophysical values, while the base case was obtained from the average petrophysical properties obtained from the reservoirs. There is no significant difference in the low case, base case, and high case porosity and net to gross in reservoir A (Fig. 5). These properties were eventually used for scenario-based deterministic and stochastic uncertainty analysis in hydrocarbon reserve estimation.
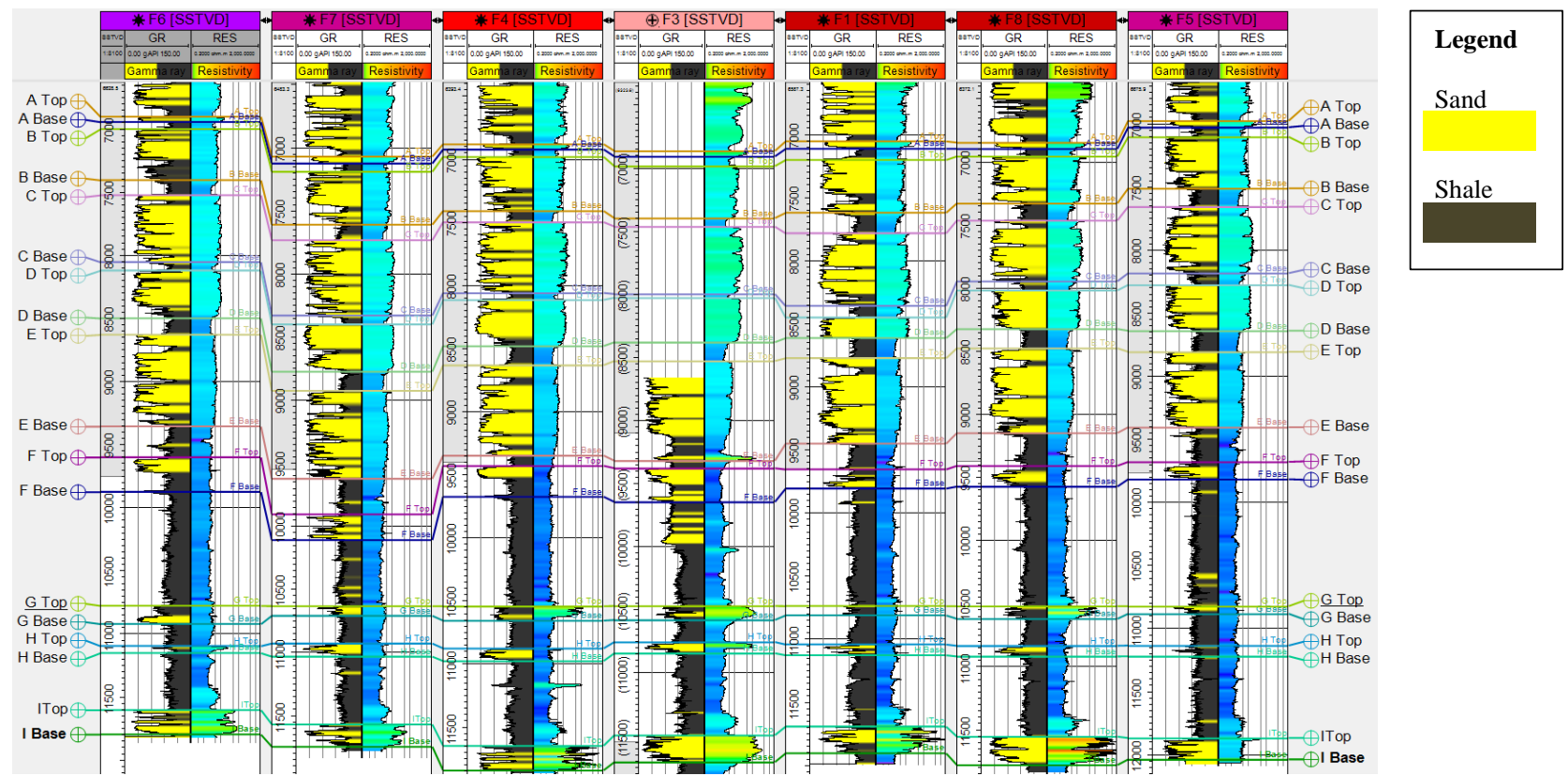

Fig. 4. Well section showing reservoir identified and correlated across Fuba Field

TABLE 1: RESULTS OF PETROPHYSICAL EVALUATION FOR RESERVOIR A

\begin{tabular}{|c|c|c|c|c|c|c|c|c|c|c|}
\hline Wells & $\begin{array}{l}\text { Reservoir } \\
\text { Top (MDft) }\end{array}$ & $\begin{array}{c}\text { Reservoir } \\
\text { Base (MDft) }\end{array}$ & $\begin{array}{l}\text { OWC } \\
\text { (MDft) }\end{array}$ & $\begin{array}{c}\text { Gross thickness } \\
\text { (ft) }\end{array}$ & $\begin{array}{c}\text { Shale } \\
\text { volume }\end{array}$ & $\begin{array}{l}\text { Net thickness } \\
\text { (ft) }\end{array}$ & NTG & $\begin{array}{c}\text { Total } \\
\text { porosity }\end{array}$ & $\begin{array}{l}\text { Effective } \\
\text { Porosity }\end{array}$ & $\begin{array}{c}\text { Water } \\
\text { Saturation }\end{array}$ \\
\hline F4 & 6930.00 & 6980.00 & 6980.00 & 50.00 & 0.10 & 45.00 & 0.90 & - & - & 0.37 \\
\hline F6 & 6957.00 & 7011.00 & 7011.00 & 54.00 & 0.11 & 48.06 & 0.89 & - & - & 0.41 \\
\hline F7 & 7101.00 & 7170.00 & 7170.00 & 69.00 & 0.08 & 63.48 & 0.92 & - & - & 0.40 \\
\hline F8 & 6910.00 & 6959.00 & 6959.00 & 49.00 & 0.14 & 42.14 & 0.86 & - & - & 0.33 \\
\hline $\mathrm{F} 1$ & 7091.00 & 7150.00 & 7141.00 & 59.00 & 0.11 & 52.51 & 0.89 & 0.34 & 0.30 & 0.38 \\
\hline F5 & 7024.00 & 7078.00 & 7066.00 & 54.00 & 0.14 & 46.44 & 0.86 & 0.28 & 0.25 & 0.33 \\
\hline F3 & 6861.00 & 6920.00 & 6926.00 & 59.00 & - & - & - & - & - & 0.10 \\
\hline \multicolumn{2}{|c|}{ Min } & & 6926.00 & 49.00 & 0.08 & 42.14 & 0.86 & 0.28 & 0.25 & 0.10 \\
\hline \multicolumn{2}{|c|}{ Max } & & 7170.00 & 69.00 & 0.14 & 63.48 & 0.92 & 0.34 & 0.30 & 0.41 \\
\hline \multicolumn{2}{|c|}{ Mean } & & 7036.14 & 56.29 & 0.11 & 49.61 & 0.89 & 0.31 & 0.28 & 0.33 \\
\hline
\end{tabular}

\begin{tabular}{|c|c|c|c|c|c|c|c|c|c|c|}
\hline Wells & $\begin{array}{c}\text { Reservoir } \\
\text { Top (MDft) }\end{array}$ & $\begin{array}{c}\text { Reservoir } \\
\text { Base (MDft) }\end{array}$ & $\begin{array}{c}\text { OWC } \\
\text { (MDft) }\end{array}$ & $\begin{array}{l}\text { Gross } \\
\text { thickness (ft) }\end{array}$ & $\begin{array}{c}\text { Shale } \\
\text { volume }\end{array}$ & $\begin{array}{l}\text { Net thickness } \\
\text { (ft) }\end{array}$ & NTG & $\begin{array}{c}\text { Total } \\
\text { porosity }\end{array}$ & $\begin{array}{l}\text { Effective } \\
\text { Porosity }\end{array}$ & $\begin{array}{c}\text { Water } \\
\text { Saturation }\end{array}$ \\
\hline $\mathrm{F} 1$ & 11745.00 & 11962.00 & 11962.00 & 217.00 & 0.22 & 169.26 & 0.78 & 0.22 & 0.21 & 0.18 \\
\hline F3 & 11484.00 & 11735.00 & 11735.00 & 251.00 & 0.10 & 225.90 & 0.90 & - & - & 0.11 \\
\hline $\mathrm{F} 4$ & 11717.00 & 11900.00 & 11900.00 & 183.00 & 0.15 & 155.55 & 0.85 & 0.23 & 0.20 & 0.19 \\
\hline F5 & 11925.00 & 12084.00 & 11944.00 & 159.00 & 0.12 & 139.92 & 0.88 & 0.26 & 0.24 & 0.54 \\
\hline F6 & 11652.00 & 11842.00 & 11842.00 & 190.00 & 0.18 & 155.80 & 0.82 & 0.25 & 0.22 & 0.21 \\
\hline F7 & 11611.00 & 11788.00 & 11788.00 & 177.00 & 0.25 & 132.75 & 0.75 & 0.21 & 0.19 & 0.23 \\
\hline F8 & 12000.00 & 12240.00 & 12240.00 & 240.00 & 0.13 & 208.80 & 0.87 & 0.35 & 0.37 & 0.15 \\
\hline \multicolumn{2}{|c|}{ Minimum } & & 11735.00 & 159.00 & 0.10 & 132.75 & 0.75 & 0.21 & 0.19 & 0.11 \\
\hline \multicolumn{2}{|c|}{ Maximum } & & 12240.00 & 251.00 & 0.25 & 225.90 & 0.90 & 0.35 & 0.37 & 0.54 \\
\hline \multicolumn{2}{|c|}{ Mean } & & 11915.86 & 202.43 & 0.16 & 169.71 & 0.84 & 0.25 & 0.24 & 0.23 \\
\hline
\end{tabular}




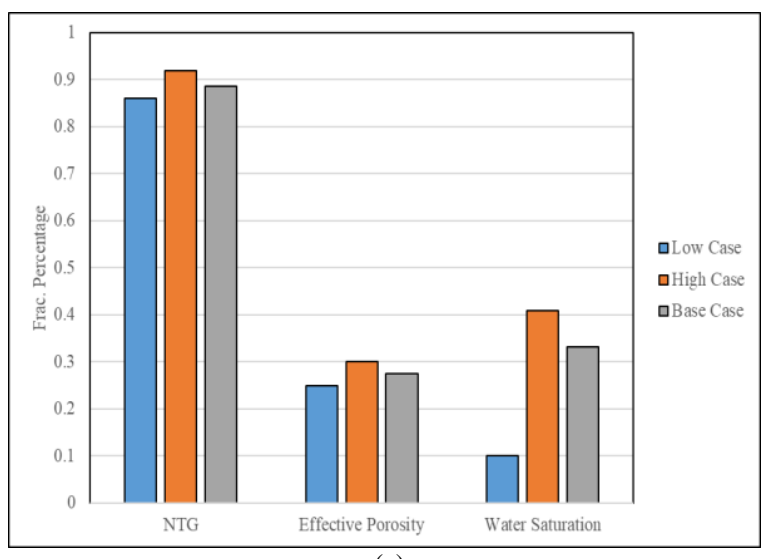

(a)

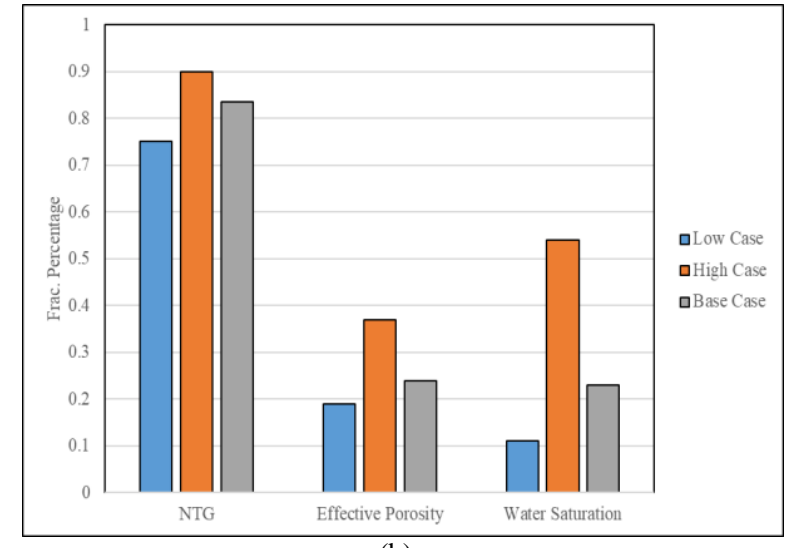

(b)

Fig. 5. Histogram showing low case, base case and a high case for petrophysical properties in (a) A reservoir and (b) I reservoir, respectively.

\section{Well Tie to Seismic Tie}

The well F1was the only well with a check shot; hence it was used for the well-seismic tie. The ISIS time statistical wavelet was used to give a near-perfect match between the seismic and synthetic seismogram with a minor bulk shift of $-3 \mathrm{~ms}$. The seismic data is zero phase with an SEG normal polarity. The positive peaks (red amplitudes in Fig. 6) are high impedance events, while the negative troughs (blue amplitudes in figure 6) are low impedance events. The welltie revealed that the sands and reservoir identified in the field all conform to high impedance events.

\section{Fault and Horizon Interpretation}

A total of twenty-nine faults were interpreted across the entire seismic data (inline and crossline) with interpretation validated with a variance edge attribute. Of the 29 interpreted faults, only F1 (synthetic fault) and F16 (antithetic fault) faults are regional, running from the top to the bottom of the seismic volume. Hence, these faults are significant for trap formation at the upper, middle, and lower sections of the field. It is no surprise that all the wells are drilled in the field falls within the closure area created by F1 and F16 faults. Horizon surfaces were also interpreted across the seismic volume based on synthetic processes. Polygons were generated across zones of interest and subsequently used to produce time surface maps, which were later depth converted to generate depth surface maps.

\section{E. Reservoir Depth Surfaces}

The check shot utilized for the generation of the velocity model for depth conversion was modified using the thirdorder instantaneous polynomial velocity function to convert surfaces from time to depth. The depth converted reservoir surfaces are presented in Fig. 8a and 8b for reservoir A and reservoir I. The depth converted surfaces show no difference in structural positioning when compared with its time equivalent. This validates the accuracy of the velocity function utilized for depth conversion. The formation of closures on these surfaces is completely fault dependent.

\section{F. Depth Residual Surfaces}

The depth uncertainties were determined using depth error maps as presented for reservoir A and reservoir I. The depth error was calculated as the difference between the reservoir tops and the reservoir surfaces (Table 3). The original map generated from the seismic interpretation process served as the base map. The base map plus the depth error multiplied with a scale factor of 2.0 , led to the high case (P90) uncertainty map generation. The base case minus the depth error multiplied by a scale factor of 2.0 formed the low case (P10) uncertainty map. The base case map is assumed to have an uncertainty of 0 .

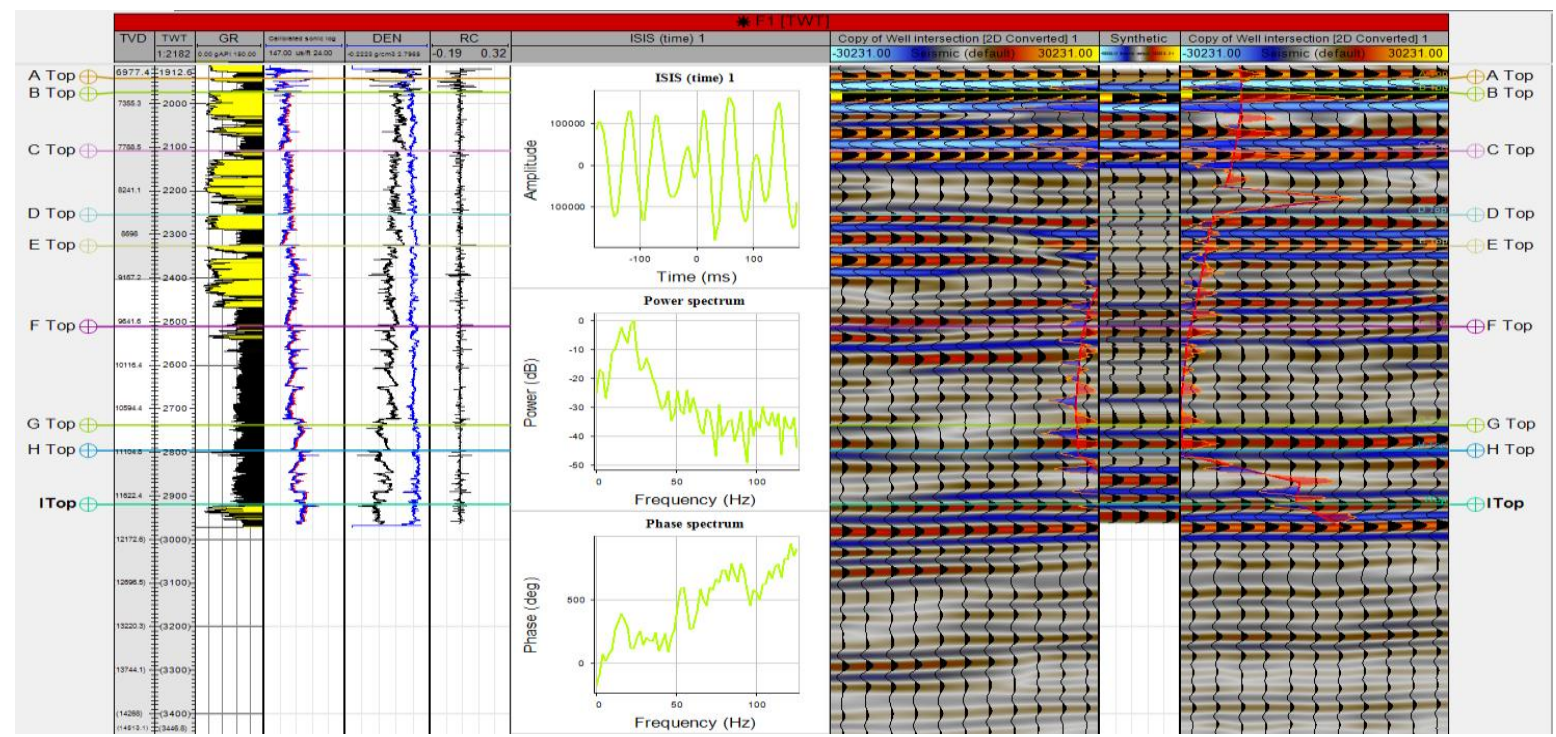

Fig. 6. Synthetic seismogram generation and seismic well tie using well F1. 


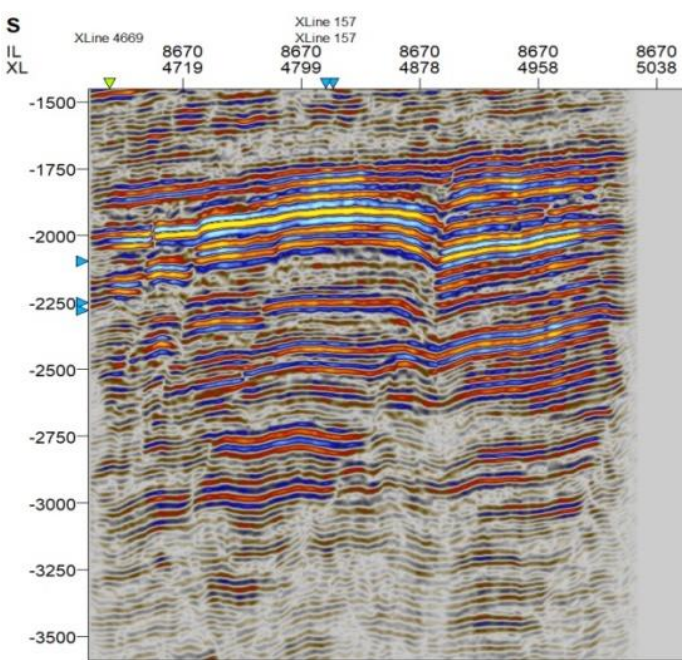

(a)

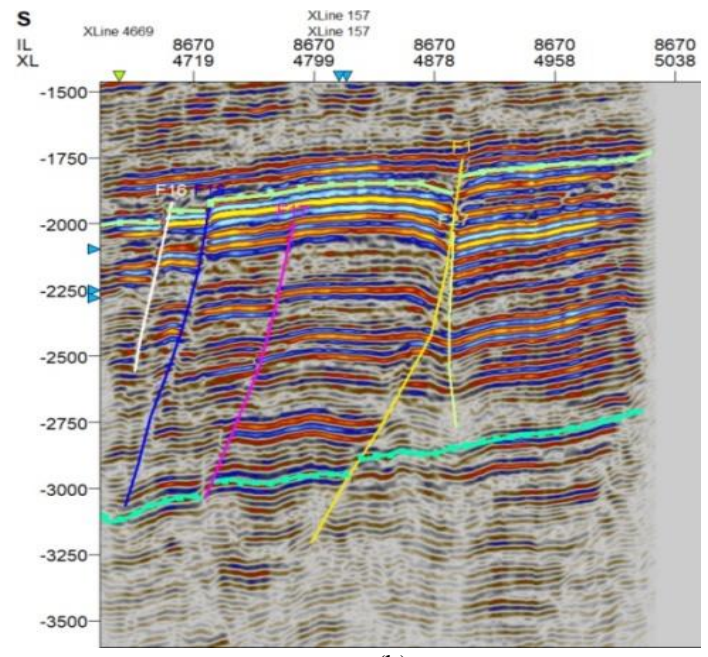

(b)

Fig. 7. Interpreted faults and horizon at inline 8670 (a) Original seismic and (b) interpreted seismic.

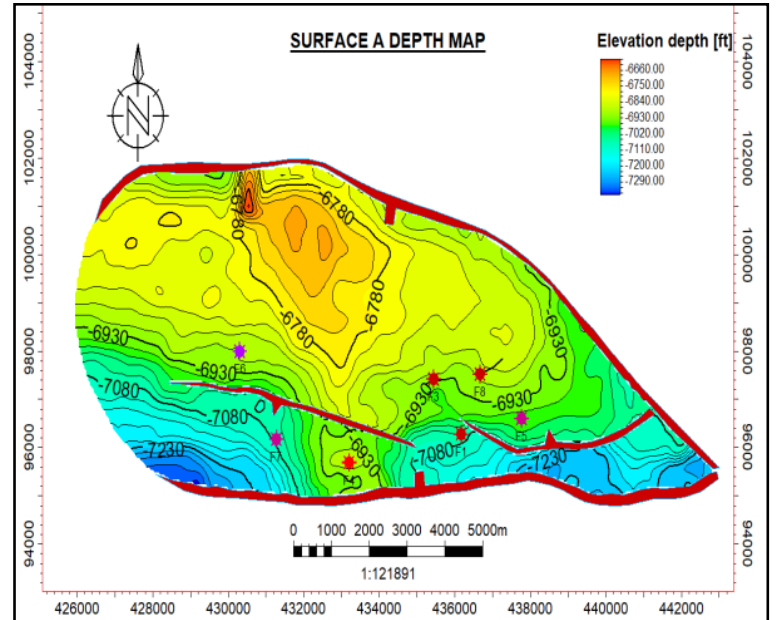

(a)

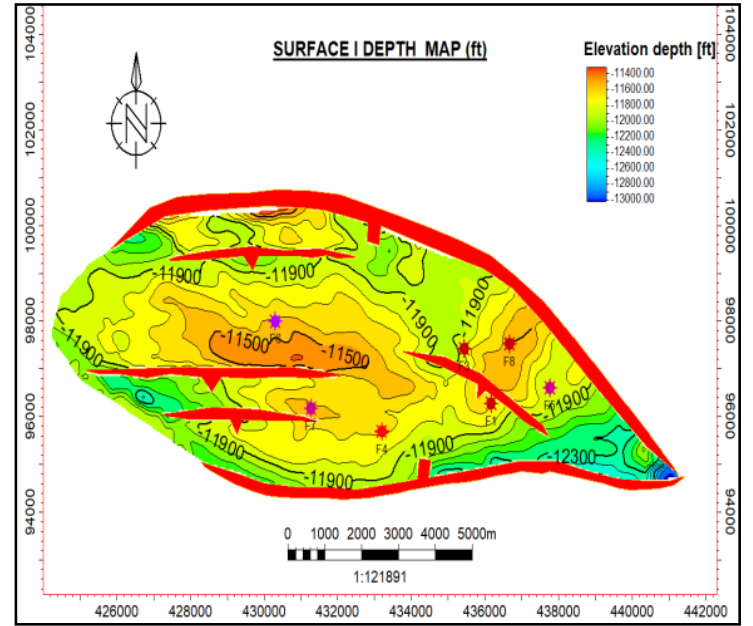

(b)

Fig. 8. Reservoir surfaces, (a) Depth Surface for reservoir A and (b) Depth Surface for reservoir I.

\begin{tabular}{|c|c|c|c|c|}
\hline Reservoir & Well & Well Top (ft) & Depth Surface (ft) & Difference $(\mathrm{ft})$ \\
\hline \multirow{7}{*}{ 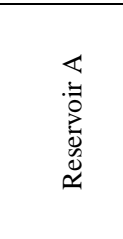 } & F1 & -7054.07 & -7053.13 & -0.95 \\
\hline & F3 & -6922.43 & -6922.43 & 0.00 \\
\hline & $\mathrm{F} 4$ & -6877.06 & -6880.86 & 3.80 \\
\hline & F5 & -6977.93 & -6971.24 & -6.69 \\
\hline & F6 & -6905.39 & -6900.65 & -4.74 \\
\hline & F7 & -7065.18 & -7070.87 & 5.69 \\
\hline & F8 & -6846.24 & -6852.85 & 6.61 \\
\hline \multirow{7}{*}{ 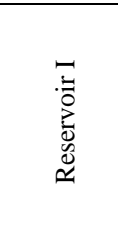 } & F1 & -11690.91 & -11690.91 & 0.00 \\
\hline & F3 & -11823.41 & -11823.41 & 0.00 \\
\hline & $\mathrm{F} 4$ & -11650.06 & -11656.67 & 6.61 \\
\hline & F5 & -11887.08 & -11877.60 & -9.48 \\
\hline & F6 & -11599.86 & -11595.11 & -4.75 \\
\hline & F7 & -11569.00 & -11564.27 & -4.73 \\
\hline & F8 & -11551.91 & -11560.33 & 8.42 \\
\hline
\end{tabular}

TABLE 4: SCENARIO-BASED DETERMINISTIC RESERVES VERSUS STOCHASTIC RESERVES ESTIMATED FOR RESERVOIR A AND RESERVOIR I

\begin{tabular}{|c|c|c|c|c|c|c|c|c|c|}
\hline \multirow[b]{2}{*}{ Reservoir } & \multirow[b]{2}{*}{ Cases } & \multicolumn{6}{|c|}{ Input Parameters } & \multirow{2}{*}{$\begin{array}{c}\text { Deterministic } \\
\text { STOIIP } \\
(\text { MMSTB) }\end{array}$} & \multirow{2}{*}{$\begin{array}{c}\text { Stochastic } \\
\text { STOIIP } \\
(\text { MMSTB }) \\
\end{array}$} \\
\hline & & Porosity & NTG & Sw & OWC (ft) & Boi & $\begin{array}{c}\text { Bulk Volume } \\
{\left[* 10^{6} \mathrm{ft}^{3}\right]}\end{array}$ & & \\
\hline \multirow{3}{*}{ Surface A } & High Case (P10) & 0.30 & 0.92 & 0.10 & -7170.00 & 1.20 & 147446.00 & 30.52 & 18.52 \\
\hline & Base Case (P50) & 0.28 & 0.89 & 0.33 & -7036.00 & 1.20 & 89583.00 & 12.46 & 13.59 \\
\hline & Low Case (P90) & 0.25 & 0.86 & 0.41 & -6926.00 & 1.20 & 43185.00 & 4.57 & 9.40 \\
\hline \multirow{3}{*}{ Surface I } & High Case (P10) & 0.35 & 0.90 & 0.11 & -12240.00 & 1.20 & 251970.00 & 58.87 & 25.56 \\
\hline & Base Case (P50) & 0.24 & 0.84 & 0.23 & -11915.86 & 1.20 & 84566.00 & 10.94 & 14.59 \\
\hline & Low Case (P90) & 0.21 & 0.75 & 0.54 & -11735.00 & 1.20 & 25027.00 & 1.51 & 7.63 \\
\hline
\end{tabular}

Hence, there is an increase in the high case rock volume compared with the base case, and there is a decrease in the low case rock volume compared with the base case map.
The resulting low case, base case, and high case uncertainty maps generated for reservoir A and reservoir I, are presented in Fig. 9. The depth uncertainty for surface A ranged from - 
6.69 to $6.61 \mathrm{ft}$ and from -9.84 to $8.42 \mathrm{ft}$ in reservoir I. The small depth error generated in both reservoirs $(<10.0 \mathrm{ft})$ confirms that the velocity models used for depth conversion are outstanding. The Low case (P90), Base case (P50), and

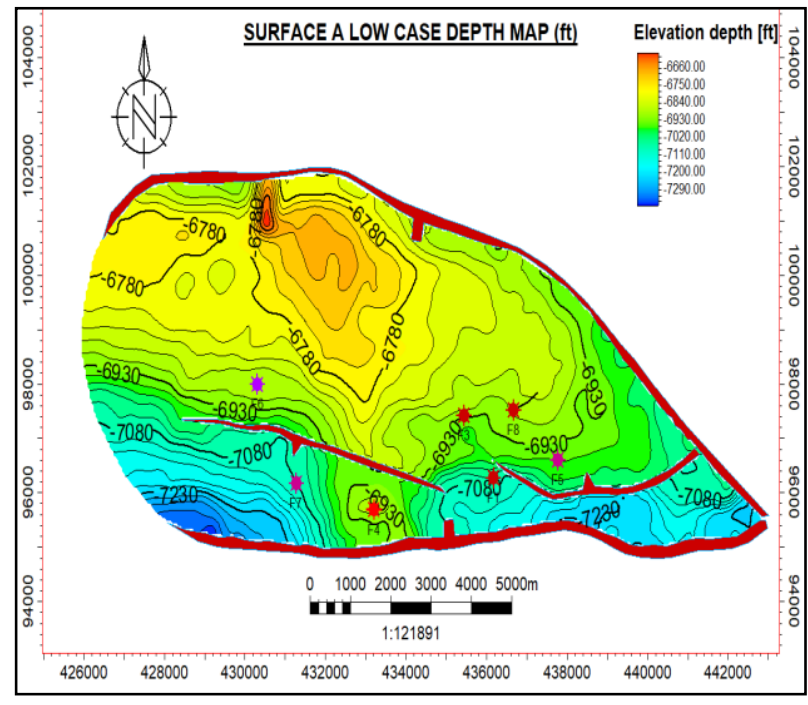

(a)

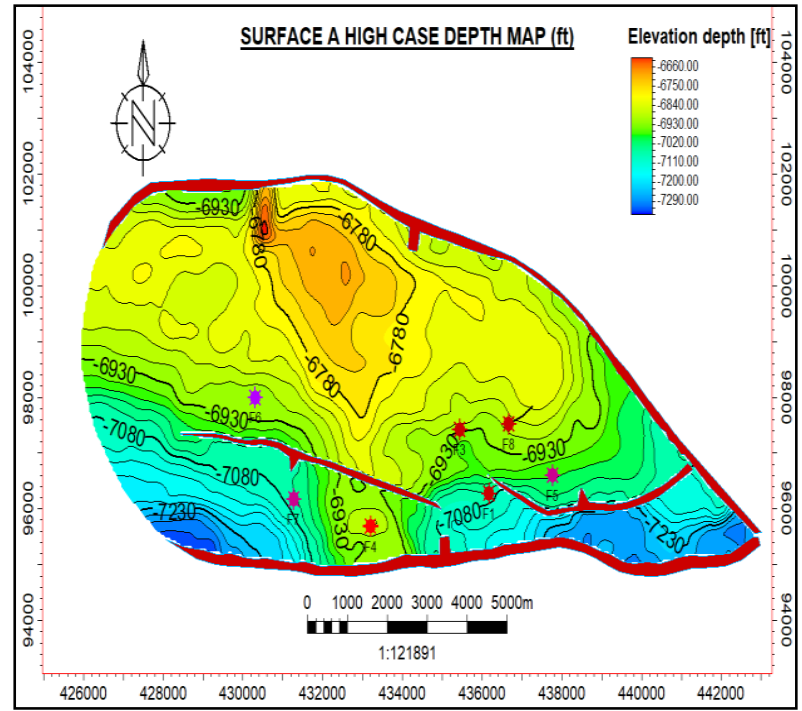

(c)

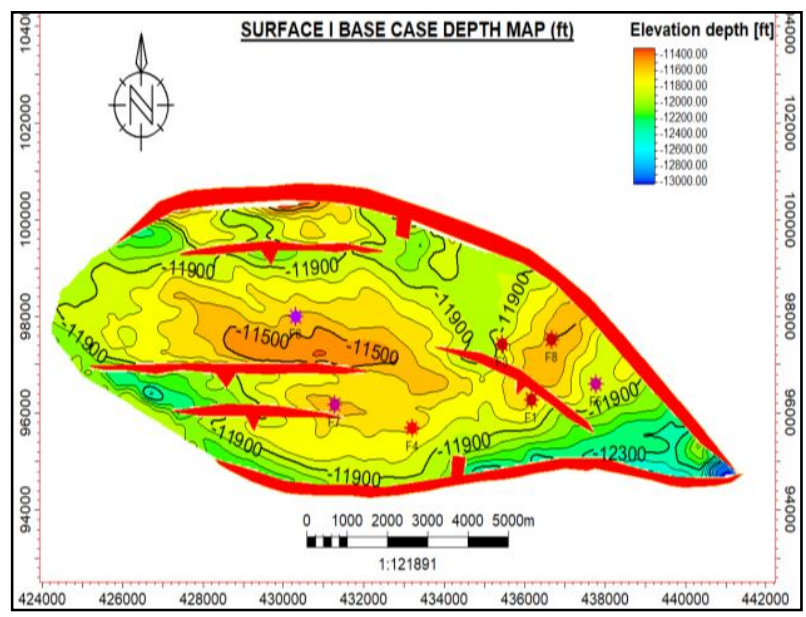

(e)
High case (P10) uncertainty maps were used in collaboration with the reservoir petrophysical properties for scenario-based.
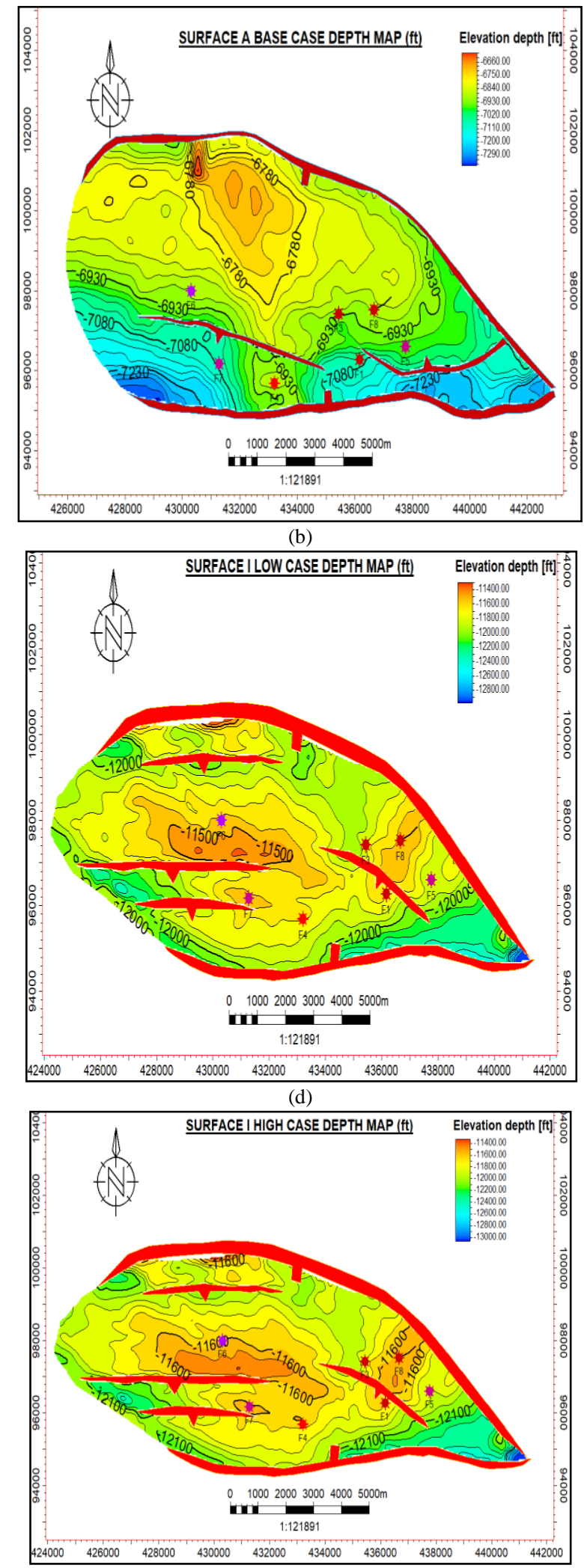

(f)

Fig. 9: Reservoir depth uncertainty surfaces for reservoir A (a) Low case, (b) Base case, (c) High Case and Reservoir I (d) low case, (e) Base case, (f) High case, respectively. 


\section{G. Deterministic and Stochastic Reserve Estimation}

The results showing the reservoir input parameters and the calculated reserves using deterministic and stochastic approaches are presented in Table 4. The lowest porosity, net to gross, and hydrocarbon saturation obtained from the petrophysical evaluation of reservoir properties in A and I reservoirs were used to determine the Low case (P90) deterministic hydrocarbon reserves. The highest of these properties were used to calculate the High case (P10) hydrocarbon reserves, while the average reservoir properties were used to calculate the Base case hydrocarbon volumes. The Bulk volume was calculated using the well tops, reservoir uncertainty surfaces, and fluid contacts. Bulk volumes estimated for the high case, base case, and low cases are $147446 \times 106 \mathrm{ft} 3,89583 \times 106 \mathrm{ft} 3$, and $43185 \times 106$ $\mathrm{ft} 3$ for reservoir A and $251970 \times 106 \mathrm{ft} 3,84566 \times 106 \mathrm{ft} 3$ and $25027 \times 106 \mathrm{ft} 3$ for reservoir I (Table 4).

Hydrocarbon reserves estimated using a scenario-based deterministic approach are 30.52 MMSTB (high case), 12.46 MMSTB (base case), and 4.57 MMSTB (low case) for reservoir A. In reservoir I, 58.87 MMSTB, 10.94 MMSTB, and 1.51 MMSTB were estimated for high case (P10), base case (P50), and low case (P10), respectively. Before stochastic hydrocarbon volumes were calculated, the reservoir properties were assigned various triangular distribution patterns in Crystal Ball software. Only the formation volume factor (Boi) was assigned a normal distribution pattern because it had a constant value (see Table 4).

The hydrocarbon reserves results calculated after 100,000 trials run in Crystal Ball software using the low case, base case and high case reservoir properties as limits are presented in Fig. 9 for reservoir A and reservoir I. The hydrocarbon volumes are presented as probabilities ranging from P0-P100. Relevant probabilities (P10, P50, and P90) representing the low case, base case and high case were extracted from the cumulative frequency curve. It was subsequently compared to the volumes calculated using the scenario-based deterministic approach (Fig. 10). The high case, base case, and low case hydrocarbon reserves reported using the stochastic approach are 18.52 MMSTB, 13.59 MMSTB and 9.40 MMSTB for reservoir $\mathrm{A}$, and 25.56 MMSTB, 14.59 MMSTB and 7.63 MMSTB for reservoir I, respectively.

The sensitivity analysis results calculated using the Crystal Ball software are presented as tornado plots in Fig. 11. The results show that the bulk volume account for the highest uncertainty in the hydrocarbon volumes calculated. It accounts for $85.9 \%$ of the uncertainty in hydrocarbon volume. In contrast, oil saturation, porosity and net to gross accounts for only $12 \%, 9.7 \%$ and $0.3 \%$ in reservoir A. These results suggest that the bulk volume is the primary control on the total hydrocarbon volumes recorded in reservoir A. Similar results were recorded in reservoir I, where bulk volume accounted for $86.1 \%$ of the entire uncertainty.

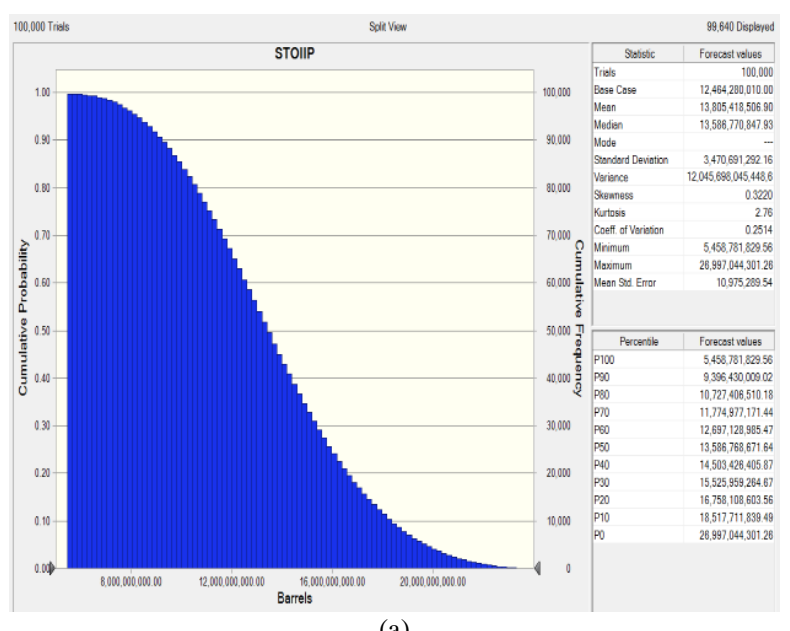

(a)

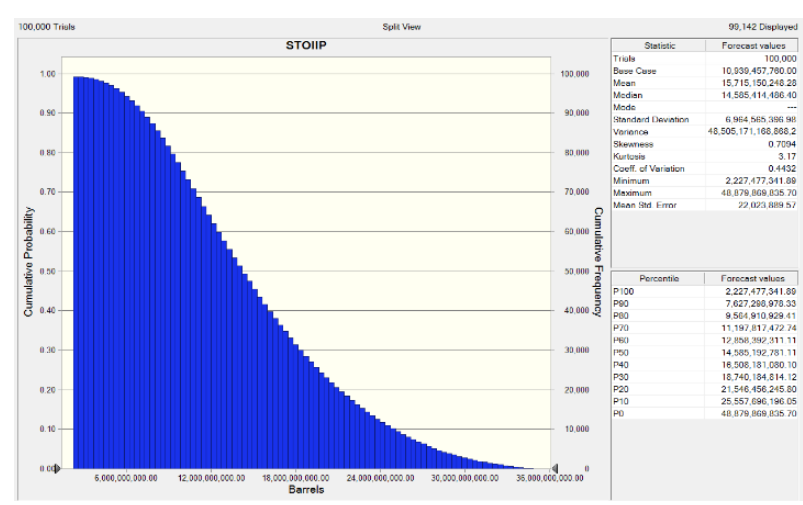

(b)

Fig. 10. Stochastic uncertainty analysis in hydrocarbon reserves using Crystal Ball software (a) Reservoir A, (b) Reservoir I.

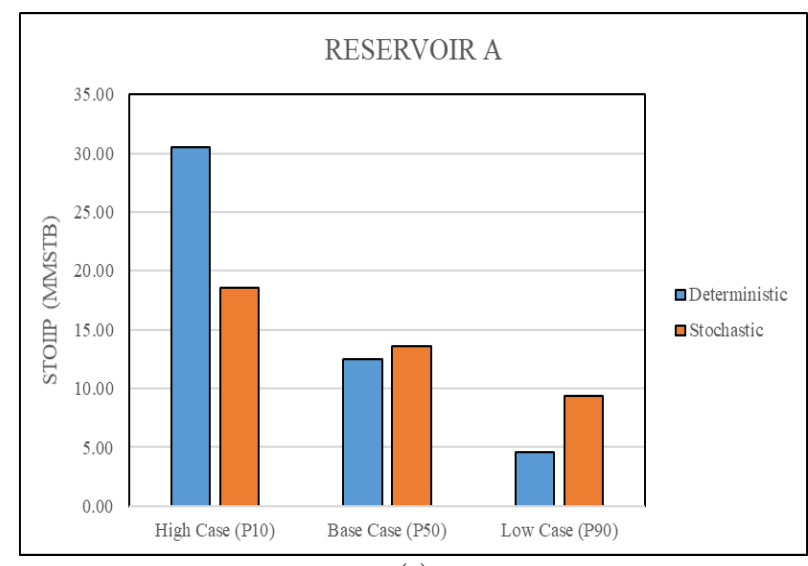

(a)

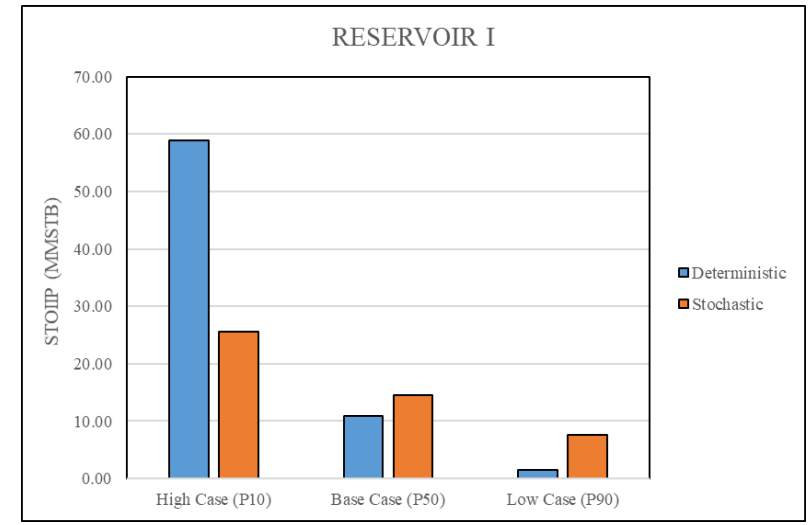

(b)

Fig. 11. Histogram plots comparing hydrocarbon reserves computed using deterministic and stochastic approaches (a) Reservoir A, (b) Reservoir I. 


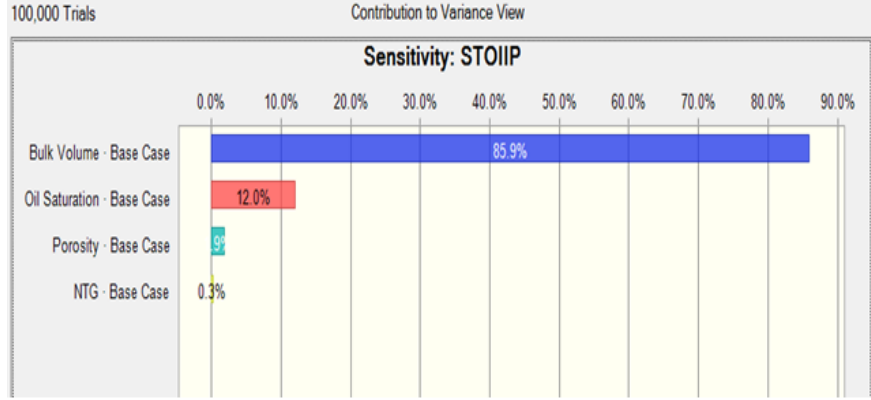

(a)

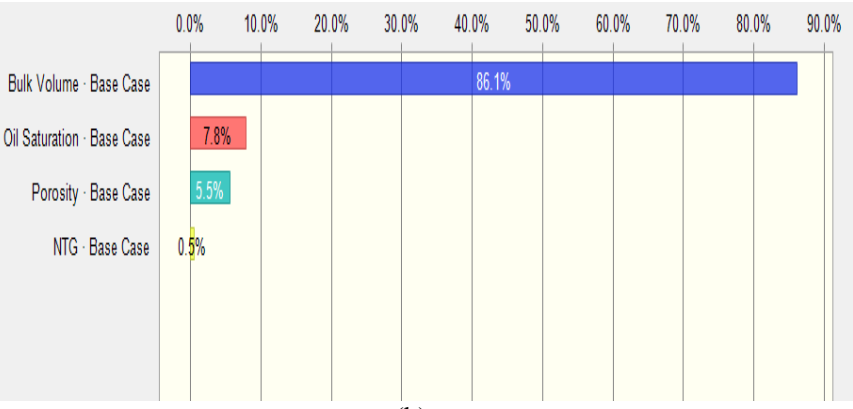

(b)

Fig. 12. Tornado plot from Crystal Ball software showing sensitivity analysis for reservoir properties (a) Reservoir A, (b) Reservoir I.

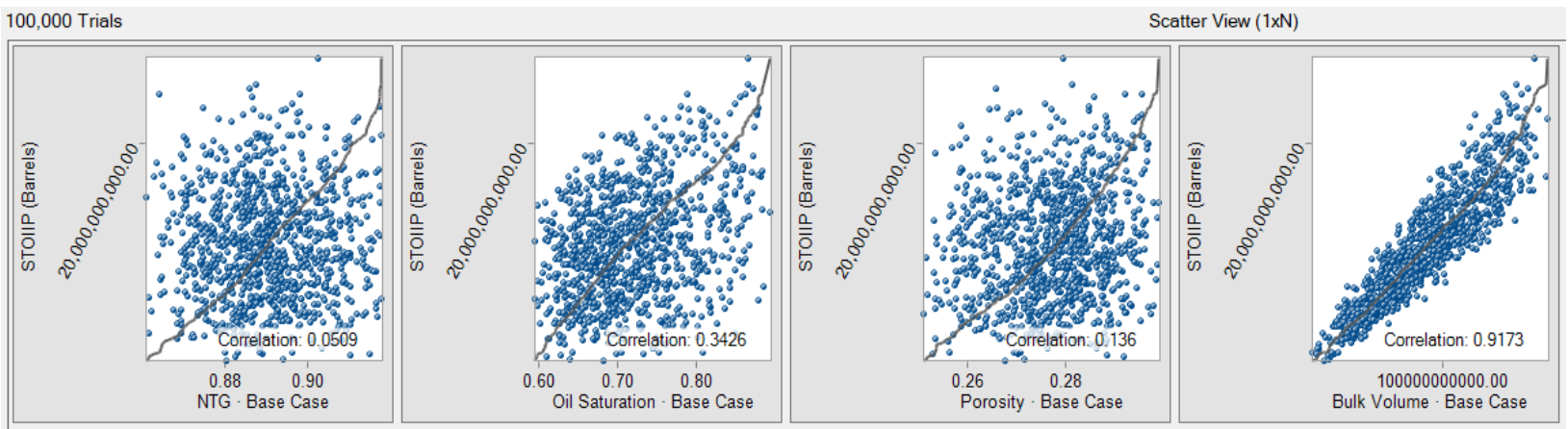

Fig. 13. Sensitivity analyses cross plots for Base case properties and hydrocarbon reserve for Reservoir A

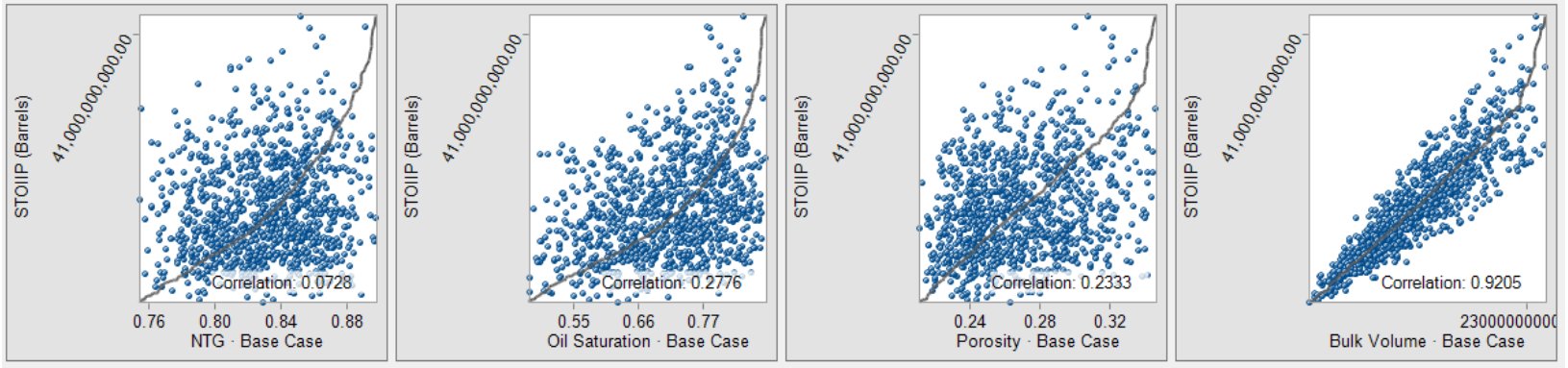

Figure 14. Sensitivity analysis cross plots for Base case properties and hydrocarbon reserve for Reservoir I.

Oil saturation, porosity and net to gross account for only about $7.8 \%, 5.5 \%$ and $0.5 \%$ of the total uncertainty in hydrocarbon reserve estimation in reservoir I.

Sensitivity analysis cross plots of base case reservoir properties against hydrocarbon volumes are presented in Fig. 13 and 14 for reservoir A and reservoir I, respectively. The cross plots show a poor correlation between hydrocarbon volumes and base case porosity, net to gross and oil saturation. Meanwhile, a very strong positive Pearson's correlation was found between base case bulk volume and hydrocarbon reserves $(\mathrm{r}=0.92)$. This suggests an increase in the reservoir bulk volume will lead to an equivalent increase in the hydrocarbon volumes and vice versa.

\section{H. Discussion}

This study was conducted to quantify the uncertainty in hydrocarbon estimates in the 'Fuba' Field, onshore Niger Delta. The study utilized both well $\operatorname{logs}$ and seismic data. Uncertainties exist in every parameter used for hydrocarbon reserve estimation. These parameters include porosity, net to gross, water saturation and bulk volume of the reservoir. To quantify uncertainties, both scenario-based deterministic and stochastic approaches were utilized, and the outcomes were compared. The hydrocarbon volumes were reported in terms of the low case (P90), base case (P50), and the high case
(P10). Afterwards, a sensitivity analysis was conducted to determine the specific reservoir properties responsible for the variability in the estimated hydrocarbon volumes.

Nine reservoir sands (A, B, C, D, E, F, G, H, I) were identified and correlated across the field using gamma-ray and resistivity logs. Two reservoirs (Reservoir A and Reservoir I) were selected for petrophysical evaluation, horizon interpretation, and hydrocarbon volumetric estimation.

Average shale volume, effective porosity, net to gross, and oil saturation are $11 \%, 31 \%, 89 \%$ and $90 \%$ for reservoir A, and $16 \%, 24 \%, 84 \%$, and $77 \%$ for reservoir I. [14] classified reservoirs having porosity ranging between 20$30 \%$ as very good quality reservoirs. Based on this classification, reservoir A and I are classed as good quality. The average petrophysical properties were considered the base case, while the highest and lowest petrophysical properties were considered the high case (P10) and low case (P90), respectively.

Structural interpretation of seismic data revealed that the field is highly faulted with synthetic and antithetic faults, which align with the faults identified in the Niger Delta. Fault and horizon interpretation revealed that the A and I reservoir's closures are collapsed crestal structures bounded by two major faults. A residual depth error, not more than $\pm 10 \mathrm{~m}$, was recorded from reservoir surface A and surface I, 
validating the velocity model's accuracy for depth conversion. Uncertainty in structure was quantified, revealing a bulk rock volume of $147446 \times 106 \mathrm{ft} 3$ (high case) $89583 \times 106 \mathrm{ft} 3$ (base case) and $43185 \times 106 \mathrm{ft} 3$ (low case) for reservoir A and $251970 \times 106 \mathrm{ft}^{3}$ (high case), $84566 \times 106 \mathrm{ft}^{3}$ (base case) and $25027 \times 106 \mathrm{ft}^{3}$ (low case) for reservoir I.

Scenario-based deterministic uncertainty analysis revealed hydrocarbon volumes of 30.52 MMSTB (high case), 12.46 MMSTB (base case) and 4.57 MMSTB (low case) for reservoir A and 58.87 MMSTB, 10.94 MMSTB and 1.51 MMSTB for reservoir I. The result shows a huge difference between the high case, base case and low case volumes. The stochastic approach revealed hydrocarbon volumes of 18.52 MMSTB, 13.59 MMSTB, and 9.40 MMSTB for reservoir A, and 25.56 MMSTB, 14.59 MMSTB and 7.63 MMSTB for reservoir I. Although there are differences in low case, base case and high case stochastic hydrocarbon volumes, the margin is not too high as recorded using the scenario-based deterministic approach. A comparison of base case hydrocarbon volumes recorded using the deterministic and stochastic approaches shows no significant differences.

Meanwhile, there is a huge difference in the low and high-case hydrocarbon reserves recorded from the deterministic and stochastic methods. The deterministic approach tends to over-estimate the high case and underestimate the low case compared with the stochastic method. The considerable difference in the low case, base case and high case hydrocarbon volumes calculated is attributed to the reservoir's bulk volume. The bulk volume accounts for $85.9 \%$ and $86.1 \%$ of the total uncertainty surrounding the estimated base hydrocarbon volumes in reservoir $\mathrm{A}$ and reservoir I. Oil saturation accounts for only $12 \%$ and $7.8 \%$ of the total uncertainty in hydrocarbon volumes in reservoir A, and reservoir I. Porosity and net to gross do not significantly impact the quantified reserves. Cross plot analysis confirmed that bulk volume is the main contributor to the enormous difference in the quantified hydrocarbon volumes in both A and I reservoirs. Hence, a slight increase or decrease in the reservoir's bulk volume will significantly impact the quantified hydrocarbon volume. Meanwhile, a variation in the reservoir's net to gross and porosity will not considerably affect the quantified volumes.

\section{CONCLUSION}

Quantifying uncertainty in hydrocarbon reserves remains crucial for the economic evaluation of any field to aid management in making informed decisions on how the resource should be produced. The deterministic hydrocarbon reserves for the low case and high case are significantly different from the stochastic reserves. Only the base case hydrocarbon volumes are similar using both methods. The stochastic method is preferred in this study because it better captures uncertainty through thousands of realizations. The bulk volume accounts for $85.9 \%$ and $86.1 \%$ of the total uncertainty surrounding the estimated base case hydrocarbon volume, while oil saturation accounts for only $12 \%$ and $7.8 \%$ for reservoir $\mathrm{A}$ and I. The reservoir bulk volume is the most crucial reservoir property for building reservoir simulation models in the Fuba field. It is the primary property that controls the uncertainty in hydrocarbon reserves estimated in reservoir A and I. Hence, preference should be given to it when developing a dynamic model for a hydrocarbon development.

\section{ACKNOWLEDGEMENT}

With immense gratitude, the Authors wish to appreciate the Petroleum Technology Development Fund (PTDF) Nigeria and the World Bank Africa Centre for Oilfield Chemical Research (ACE-FOR) Grant for supporting this work. We are sincerely grateful to the Centre of Petroleum Geoscience (CPG) Lab and DeGeoid Integrated Geoservices Limited for allowing us to use their laboratories.

\section{REFERENCES}

[1] Caldwell, R. H., and Heather, D. I. Characterizing Uncertainty in Oil and Gas Evaluations. Society of Petroleum Engineers. doi:10.2118/68592-MS, 2001.

[2] Rahimov, F. V., and Huseynov, R. M. Risk and Uncertainty Assessment While Estimating Reserves, Bull. Society of Petroleum Engineer; DOI: 10.2118/189019-MS, 2017

[3] Samimi, A.K., and Karimi, G. Sensitivity and uncertainty analysis of original oil-in-place in carbonate reservoir modelling, A case study. Petroleum and Coal 56(3) 332-338, 2014

[4] Hamada, G., Almajed, A., Okasha, A., Taha, A., and Algathe, A. Uncertainty analysis of Archie's parameters determination techniques in carbonate reservoirs. Journal of Petroleum Exploration and Production Technology. 2012

[5] Doust, H. and Omatsola, E. Niger Delta: Edwards, J.D. and Santogrossi, P.A. (eds.), Divergent/passive Margin Basins, AAPG Memoir 48, 239-248.,1990.

[6] Short, K.C., Stauble, A.J. Outline of Geology of Niger Delta. Am. Assoc. Petr. Geol. Bull., 51(5): 761-779, 1967.

[7] Ekweozor, C. M., and Daukoru, E. M. Petroleum Source Bed Evaluation of Tertiary Niger Delta. American Association of Petroleum Geologists Bulletin, Vol. 70, 48-55, 1984.

[8] Weber, K.J., and Daukoru, E.M. Petroleum geology of the Niger Delta. Ninth World Petroleum Congress. Tokyo. 2: 202 - 221, 1975.

[9] Adegoke, O.S., Oyebamiji, A.S., Edet, J.J., Osterloff, P.L., Ulu, O.K. Cenozoic foraminifera and calcareous nannofossil biostratigraphy of the Niger Delta. Cathleen Sether, United States, 570, 2017.

[10] Clavier, C., Hoyle, W. R., and Meunier, D. Quantitative Interpretation of TDT Logs. Parts I and II: Journal of Petroleum Technology, Vol 23, 743-763, 1971.

[11] Gluyas, J., and Swarbrick, R. Petroleum Geosciences. Publication. Blackwell. Publishing, 32, 2004.

[12] Archie, G.E. The Electrical Resistivity Log as an Aid in Determining Some Reservoir Characteristics. Trans, 54-62, 1942.

[13] Woodhouse, R., and Warner, H.R. Sw and Hydrocarbon Pore Volume Estimates in Shaly Sands - Routine Oil-Based-Mud Core Measurements Compared with Several Log Analysis Models. Society of Petroleum Engineers Annual Technical Conference and Exhibition, Dallas, Texas, 2005.

[14] Rider M. "The Geological Interpretation of Well Logs", Blackie, Glasgow, 151-165. 1986 